\title{
Green Criminology e prevenção a danos ambientais em áreas protegidas na Amazônia
}

A era dos extremos foi palco de debates sobre preservação ambiental. As áreas protegidas emergiram nesse cenário como um instrumento protetivo, objetivando resguardar os recursos naturais e o modo de vida das populações tradicionais em uma área geográfica específica. Contudo a simples existência das unidades de conservação não impediram que condutas ilícitas ocasionassem danos a tais espaços. O estudo objetivou a proposição de parâmetros preventivos para controle de infrações ambientais em áreas protegidas análogas, através da identificação do perfil genérico desses espaços protegidos, caracterização das infrações ambientais, e, da identificação dos parâmetros de prevenção à infrações ambientais. A pesquisa possui naturez descritiva, quanto aos seus objetivos, e, documental em relação aos procedimentos metodológicos utilizados, abrangendo cinco Unidades de Conservação federais do Município Amazônico de Guajará-Mirim. $O$ estudo evidenciou que: a irregularidade dos aspectos fundiários constitui fator de conflitos em três áreas analisadas, influenciando diretamente nas pressões e ameaças das unidades de conservação; não há demarcação dos limites físicos nos espaços territoriais especialmente protegidos da amostra; $60 \%$ da amostra possui emergências ambientais, totalizando 15.586 hectares de queimadas e 281 hectares de desmatamento; há insuficiência de recursos humanos, pois a gestão das unidades de conservação é realizada em $80 \%$ da amostra por uma única pessoa, responsáveis por realizar as ações críticas de proteção e prevenção de atividades ilegais na área protegida; foram lavrados 21 autos de infrações ambientais, motivados por ações planejadas, denúncias e planos de fiscalização estabelecidos; nos registros pesquisados, inexiste autos de infração em três das cinco unidades de conservação da amostra por ações planejadas, denúncias e planos de fiscalização estabelecidos; nos registros pesquisados, inexiste autos de infração em três das cinco unidades de conservação da amostra,
predominando ilícitos relacionados à fauna; e, quanto a autoria, o gênero masculino predominou em $81 \%$ dos registros. Verificou-se três parâmetros de prevenção à infrações ambientais: predominando ilícitos relacionados à fauna; e, quanto a autoria, o gênero masculino predominou em $81 \%$ dos registros. Verificou-se três parâmetros de prevenção à infrações ambientais: infração ambiental através da compreensão situacional. Concluiu-se que somente a implantação das unidades de conservação não legitima a preservação ambiental. Prevenção a danos ambientais são e serão, sempre, a forma mais eficaz de controlar os impactos negativos ao ambiente.

\section{Green Criminology and prevention of environmental damage in protected areas in the Amazon} \begin{abstract}
The era of extremes was scene of debates on environmental preservation. Protected areas emerged in this scenario as a protective instrument, aiming to protect the natural resources and
way of life of traditional populations in a specific geographic area. However, the mere existence of protected areas did not prevent illegal acts from harming those spaces. The study aimed at proposing preventive parameters for the control of environmental infractions in similar protected areas, through the identification of the generic profile of these protected spaces, da characterization of environmental infractions, and of the identification of the parameters of prevention to the environmental infractions. The research is descriptive in terms of its objective and documental in relation to the methodological procedures used, covering five Federal Conservation Units of the Guajará-Mirim Amazonian Municipality. The study showed that: the irregularity of the land aspects is a factor of conflicts in three analyzed areas, directly influencing the pressures and threats of conservation units; there is no demarcation of the physical limits in the speciall pros

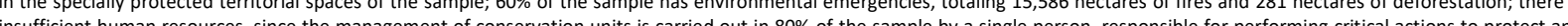
insufficient human presources, prevent illegal activities in the protected area; 21 records of environmental infractions were drawn up, motivated by planned actions, denunciations and established inspection plans; in the searched records, there are no indications of infraction in three of the five protected areas of the sample, predominating illicit related to the fauna; and, in terms of authorship, the male gender predominated in $81 \%$ of the records. Three parameters of prevention to environmental infractions were verified: actions of inspection to the natural capital in protected areas; Land regularization, as an instrument of environmental justice; And environmental education as a way of perceiving environmental infraction through situational understanding. It was concluded that only the implementation of conservation units does not legitimize environmental preservation. Prevention of environmental damage is and will always be the most effective way to control negative impacts on the environment.
\end{abstract}

Keywords: Green Criminology; Environmental Infractions; Prevention; Amazon.

Topic: Legislação e Direito Ambiental

Reviewed anonymously in the process of blind peer.

Cíntia Rosina Flores (id

Universidade do Vale do Taquari, Brasil

http://lattes.cnpq.br/7655151657670894

http://orcid.org/0000-0002-4384-3097

rosinaflores@gmail.com

Odorico Konrad

Montanuniversität Leoben, Áustria

http://lattes.cnpq.br/9946679953072196

okonrad@univates.br

Josmar Almeida Flores (id

Universidade do Vale do Taquari, Brasil

http://lattes.cnpq.br/7617549273492752

http://orcid.org/0000-0002-4111-4536

josmarflores@gmail.com
Received: 20/07/2017

Approved: 21/10/2017
Referencing this:

FLORES, C. R.; KONRAD, O.; FLORES, J. A.. Green Criminology e prevenção à danos ambientais em áreas protegidas na Amazônia. Revista Ibero-Americana de Ciências Ambientais, v.8, n.4, p.281-294, 2017. DOI: http://doi.org/10.6008/SPC2179-6858.2017.004.0023 


\section{INTRODUÇÃO}

O breve século XX, ou a era dos extremos, delineado por Hobsbawm (2005) como palco de debates sobre uma das questões centrais deste período a ecologia, teve premente na sociedade de risco descrita por Beck (2011) a preservação ambiental, envolvendo atores de diversas esferas, entre eles estão governos, pesquisadores, cidadãos e organismos internacionais na busca de estratégias alternativas de reapropriação da natureza, em sentido lato perquirindo limitar as ações nocivas ao ambiente na construção de um futuro sustentável (LEFF, 2009). No centro dessas discussões o dano ambiental é assunto de primeira ordem, uma única violação ambiental pode produzir centenas, milhares ou mesmo milhões de vítimas humanas e nãohumanas, causando, por vezes, verdadeiros desastres ambientais (LYNCH et al., 2013; BRAGA, 2004; WHITE, 2003).

As áreas protegidas emergiram nesse cenário como um instrumento protetivo, objetivando resguardar os recursos naturais e o modo de vida das populações tradicionais em uma área geográfica específica (MEDEIROS, 2003). Atualmente esses espaços são a pedra angular das políticas públicas nacionais e internacionais de conservação dos ecossistemas in situ em nível planetário, representando cerca de 15\% da superfície da terra (NICOLLE, 2017; IUCN, 2016; DUDLEY et al., 2006).

O Brasil possui o maior sistema mundial de áreas protegidas, cobrindo aproximadamente 220 milhões de hectares. Este sistema conservacionista, da biodiversidade e dos serviços ecossistêmicos, teve sua expansão centralizada nas décadas de 1990 até meados de 2000, contudo, observa-se um aumento de destruição e danos aos recursos naturais em unidade de conservação (BERNARD et al., 2014)

Portanto, a simples existência das unidades de conservação, inicialmente denominadas áreas protegidas, não impediram que condutas ilícitas ocasionassem danos a tais espaços. Na Amazônia o cenário tem-se agravado devido à proximidade com zonas economicamente acessíveis à exploração econômica, como extração de madeira e pecuária, expondo as unidades de conservação à pressão de atividades ilegais (BARRETO et al., 2009a; PINHEIRO, 2015).

Nesse cenário, a teoria contemporânea green criminology emerge como uma metodologia de efetividade às áreas protegidas, através do estudo das condutas lesivas ao ambiente (LYNCH et al., 2013; PUCCl, 2013), com base nas suas áreas de abrangência dano e destruição, normas jurídicas e regulação ambiental (SOUTH et al., 2014a). Essa tipologia criminológica contemporânea percebe os delitos ao ambiente enquanto fenômeno complexo e diversos em dimensões, considerando sua multiplicidade de fatores culturais, econômicos, sociais e ambientais (ELVAN, 2014; CINTRA, 2006).

A pesquisa doutoral objetivou a proposição de parâmetros preventivos, com vista ao controle de ocorrências das infrações ambientais em Unidades de Conservação federais do Município de Guajará-Mirim, para tanto foi: identificado o perfil genérico desses espaços protegidos; caracterizado as infrações ambientais através da organização de banco de dados das condutas ilícitas ocorridas na área em análise; e, com base nos padrões das transgressões, identificado parâmetros de prevenção à infrações ambientais para serem aplicados à Unidades de Conservação em situações análogas à pesquisa. 


\section{METODOLOGIA}

A pesquisa possui natureza descritiva, quanto aos seus objetivos, e, documental em relação aos procedimentos metodológicos utilizados, considerando que os dados advêm de fontes primárias. $\mathrm{O}$ universo deste trabalho abrange as cinco Unidades de Conservação federais do Município Amazônico de GuajaráMirim, Estado de Rondônia, compreendendo dois parques e três reservas extrativistas. O lapso temporal teve como marco inicial o ano de ano no qual foi implantado o Instituto Chico Mendes da Biodiversidade (ICMBIO), a delimitação final ocorreu em dezembro do ano de 2015.

A coleta dos dados compreendeu dois momentos, identificação do perfil genérico das Unidades de Conservação e caracterização dos crimes ambientais ocorridos nas mesmas. Á delimitação do perfil genérico das áreas protegidas buscou a identificação e a descrição da unidade de conservação da amostra, embasando-se no perfil empregado pelo 'Método para Avaliação Rápida e a Priorização da Gestão de Unidades de Conservação - Rappam' (ICMBIO, 2015).

$\mathrm{Na}$ identificação do perfil da amostra a coleta ocorreu através de informações disponíveis em de dois bancos de dados virtuais. Primeiro no Painel Dinâmico do ICMBIO, opção síntese de informações sobre unidades de conservação, através das variáveis: Informações Gerenciais - recursos humanos; Informações ecológicas - espécies ameaçadas de extinção; Emergências ambientais - desmatamento e área queimada; e Efetividade de gestão - pesquisa, avaliação e monitoramento.

Segundo no Cadastro Nacional de Unidades de Conservação (Ministério do Meio Ambiente) as informações foram obtidas a partir da emissão do 'Relatório Parametrizado de Unidade(s) de Conservação', selecionando as opções: Esfera administrativa - federal; Unidade da Federação (UF) - Rondônia; Município - Guajará-Mirim; Formato do Relatório - HTML Formatado; Informações gerais; Atos legais; Caracterização - fatores sociais; Gestão/infraestrutura - comunicação; Gestão - aspectos fundiários; Gestão - recursos humanos; Gestão - visitação; e Gestão - educação ambiental.

Os dados dos aspectos fundiários e da forma de acesso as unidades de conservação foram comparados as informações do tema contidas no plano de manejo das áreas pesquisadas, disponíveis virtualmente no sítio do ICMBIO. A organização do banco de dados da caracterização dos crimes ambientais deu-se a partir de inventário dos processos administrativos de competência do Instituto Chico Mendes da Biodiversidade (ICMBIO), responsável pelas Unidades de Conservação federais no Brasil. Aplicou-se como parâmetro o procedimento utilizado por Cintra (2006): organização de banco de dados a partir da análise qualitativa e quantitativa da ocorrência de danos ambientais através de consulta de documentos legais registrados por orgãos competentes.

A coleta das informações ocorreu, fisicamente, na Coordenação Regional CR1 - Porto Velho. Foram analisados, nos processos administrativos, os autos de infração, relatório de fiscalização e a ordem de fiscalização, através das seguintes variáveis: Autuado - suposto infrator ambiental; Município de residência do autuado; Data da autuação; Sanções administrativas aplicadas; Valor da multa - quando aplicado; Fundamentação legal da conduta; Descrição da infração; Localização da ocorrência - lato sensu (unidade de conservação, zona de amortecimento, área circundante/entorno, externo com dano ocorrendo na área 
protegida) e stricto sensu (local); Classificação da motivação da ação fiscalizatória - ação planejada, rotina (escala de serviço), determinação judicial/Ministério Público, Denúncia e/ou emergência, plano de fiscalização estabelecido; e Histórico, resultados e conclusões.

Conforme procedimento adotado por Elvan (2014), a tipologia as infrações ambientais foram classificadas de acordo com a norma ambiental competente. O Decreto n6514/2008, prevê seis espécies ilícitas: contra a fauna, contra a flora, relativas à poluição, contra o ordenamento urbano e o patrimônio cultural, contra a administração ambiental e cometidas exclusivamente em unidades de conservação.

Visando dar efetividade a pesquisa foi protocolado em 24 de junho de 2013, sob o número 40136-1, no Sistema de Autorização e Informação em Biodiversidade (SISBIO) solicitação, com finalidade científica, de autorização para a execução da referida pesquisa com vistas a caracterizar os crimes ambientais ocorridos nas unidades de conservação federais do Município de Guajará-Mirim desde a implantação do ICMBIO, sendo que em 18 de julho de julho de 2013 o Instituto Chico Mendes de Conservação da Diversidade Biológica (ICMBIO) emitiu autorização/licença referente a solicitação acima descrita através do Código de Autenticação nำ31659358.

\section{Operacionalização dos dados}

$\mathrm{Na}$ caracterização dos crimes ambientais empregou-se, às informações do banco de dados, o instrumento técnico-científico da análise criminal estratégica (ROTH, 2013), que visa estudar as variações dos indicadores de criminalidade quantitativa e qualitativamente para descrever e explicar o fenômeno. Os dados foram ordenados a partir da planilha eletrônica do Software Excel e analisados com estatísticas descritivas para construção das tabelas e gráficos, buscando entender a interdependência entre os pontos estudados (SOTHE et al., 2017).

$\mathrm{Na}$ identificação dos parâmetros preventivos comparou-se os padrões das condutas danosas ao ambiente, verificados após a caracterização das infrações, às áreas de abrangência da green criminology descritas por South et al. (2014a): Dano e destruição ambiental - proscritos como crimes e/ou infrações; Normas jurídicas ambientais - administrativas, penais e civis, aplicadas através de uma agência governamental ou do sistema de justiça criminal; e Regulação ambiental - sistemas e processos para fins de proteção e monitoramento.

\section{RESULTADOS E DISCUSSÃO}

As seções seguintes apresentam os principais resultados do estudo documental: as análises do perfil das cinco unidades de conservação federais, a caracterização das infrações ambientais praticadas nas áreas da amostra e, por fim, os parâmetros de prevenção à danos ambientais identificados. Os dados primários revelaram que as cinco unidades de conservação estudadas, perfazem 1.434.046ha, tendo sido criadas nas últimas quatro décadas. Na categoria proteção integral estão os Parques Nacionais do Pacaás Novos e da Serra da Cutia, como uso sustentável as Reservas Extrativistas Barreiro das Antas, Rio Cautário e Rio Ouro Preto, conforme se pode visualizar na tabela 1. Quanto ao perfil genérico das unidades de conservação 
estudas observou-se que o total de recursos humanos é discrepante entre o MMA e o ICMBio. Manteve-se o número apontado pelo ICMBio considerando a atualização da informação.

Tabela 1: Perfil genérico das Unidades de Conservação federais de Guajará-Mirim.

\begin{tabular}{|c|c|c|c|c|c|c|}
\hline \multicolumn{2}{|c|}{ Unidade de Conservação: } & Pacaás Novos & Serra da Cutia & Barreiro das Ant: & Cautário & Rio Ouro Preto \\
\hline \multicolumn{2}{|c|}{ Tipologia } & Parque Nacional & Parque Nacional & Resex & Resex & Resex \\
\hline \multicolumn{2}{|c|}{ Grupo } & Proteção integral & Proteção integral & Uso sustentável & Uso sustentável & Uso sustentável \\
\hline \multicolumn{2}{|c|}{ Criação } & $21 / 09 / 1979$ & $01 / 08 / 2001$ & 08/08/2001 & $08 / 08 / 2001$ & $14 / 03 / 1990$ \\
\hline \multicolumn{2}{|c|}{ Área (há) } & 764.801 & 283.611 & 107.234 & 73.817 & 204.583 \\
\hline \multicolumn{2}{|c|}{ Município(s) abrangido(s) } & 6 & 2 & 1 & 1 & 2 \\
\hline \multicolumn{2}{|c|}{ Acesso } & terrestre & fluvial & fluvial & fluvial & Terrestre \\
\hline \multicolumn{2}{|c|}{ Plano de Manejo } & 2009 & 2008 & 2014 & não & 2014 \\
\hline \multicolumn{2}{|c|}{ Recursos humanos } & 2 & 1 & 1 & 1 & 1 \\
\hline \multicolumn{2}{|c|}{ Comunicação } & Não & não & não & não & Não \\
\hline \multicolumn{2}{|c|}{ Educação ambiental } & Não & não & não & $\operatorname{sim}$ & Não \\
\hline \multicolumn{2}{|c|}{ Pesquisa, avaliação e monitoramento } & baixa efetividade & baixa efetividade & baixa efetividade & baixa efetividade & baixa efetividade \\
\hline \multirow{3}{*}{$\begin{array}{c}\text { Presença humana } \\
\text { interior }\end{array}$} & não tradicional & 0 & 0 & 0 & 0 & 0 \\
\hline & tradicional & 0 & 0 & 27 & 45 & 642 \\
\hline & Indígena & 0 & 0 & 0 & 0 & 0 \\
\hline \multirow{3}{*}{$\begin{array}{c}\begin{array}{c}\text { Presença humana } \\
\text { entorno }\end{array} \\
\end{array}$} & não tradicional & 0 & 1.560 & 1.301 & 0 & 0 \\
\hline & tradicional & 0 & 310 & 149 & 243 & 1.384 \\
\hline & Indígena & 350 & 1.100 & 1.062 & 350 & 0 \\
\hline \multicolumn{2}{|c|}{ Aspectos fundiários } & Regularizado & não regularizado & $\begin{array}{l}\text { parcialmente } \\
\text { regularizado }\end{array}$ & regularizado & não regularizado \\
\hline \multicolumn{2}{|c|}{ Demarcação dos limites } & Não & não & não & não & Não \\
\hline \multicolumn{2}{|c|}{ Área queimada 2016} & 12.788 (ha) & 2.474 (ha) & não há registro & não há registro & 324 (ha) \\
\hline \multicolumn{2}{|c|}{ Desmatamento *PRODES 2016} & 17 (ha) & 95 (ha) & não há registro & não há registro & 169 (ha) \\
\hline \multirow{2}{*}{\multicolumn{2}{|c|}{ Espécies ameaçadas de extinção }} & 12 & 4 & 0 & 0 & 1 \\
\hline & & \multicolumn{5}{|c|}{ Informações Complementares } \\
\hline \multicolumn{2}{|c|}{ PARNA Pacáas Novos } & \multicolumn{5}{|c|}{$\begin{array}{l}\text { - O entorno é habitado por uma comunidade de assentados (Distrito de Surpresa). } \\
\text { - Sofre pressão de caca, garimpo, desmatamento e grilagem de terras. }\end{array}$} \\
\hline \multicolumn{2}{|c|}{ Resex do Rio Ouro Preto } & \multicolumn{5}{|c|}{$\begin{array}{l}\text { - Limita a ocupação antrópica das áreas protegidas, à noroeste do bloco de proteção. } \\
\text { - Compreende manancial de águas, formadas por relevantes nascentes, rios e igarapés. }\end{array}$} \\
\hline \multicolumn{2}{|c|}{ Resex do Rio Cautário } & \multicolumn{5}{|c|}{$\begin{array}{l}\text { - Inserida em uma região com áreas utilizadas para pecuária e expansão da fronteira agrícola do } \\
\text { Estado. }\end{array}$} \\
\hline
\end{tabular}

Legenda: PRODES - Projeto de Monitoramento do Desmatamento na Amazônia Legal por Satélite.

Observou-se que a Reserva Extrativista do Rio Cautário não possui plano de manejo, mesmo já tendo sito ultrapassado, em mais de uma década, o prazo máximo legal de cinco anos para elaboração. As unidades de conservação que publicaram tal instrumento técnico, o fizeram, também, fora do prazo previsto. É este documento que, de acordo com os objetivos da unidade de conservação, estabelece seu zoneamento e as regras que irão presidir o uso da área e o manejo dos recursos naturais (BRASIL, 2000). Assim, o descumprimento da implantação do plano de manejo atinge a eficácia da finalidade de tais espaços protegidos, refletindo negativamente ambiental, social e economicamente (FERREIRA, 2013).

O estudo evidenciou que a irregularidade dos aspectos fundiários constitui fator de conflitos em três áreas analisadas, influenciando diretamente nas pressões e ameaças das unidades de conservação. Para Reydon (2011) ,a questão do desmatamento na Amazônia está vinculada à ausência de governança fundiária no país, remontando a processo histórico; no entanto, sua implementação nos espaços protegidos é uma ferramenta a ser utilizada para conter os processos de degradação ambiental através da apropriação indevida de grandes extensões de terras, sobretudo para fins de concentração fundiária (BARATA, 2011).

A regularização fundiária das áreas protegidas permite dominialidade da terra com a concessão de direito real de uso às populações tradicionais residentes na localidade, dificultando a ocorrência de conflitos fundiários, como revelado no caso da grilagem de terras no Parna Pacáas Novos e da proposta de redefinição das terras da Resex do Rio Ouro Preto com exclusão de $15 \%$ sob a justificativa de antropização da área. 0 
combate ao estigma de que ocupações ilegais são passíveis de regularização é vital para evitar novas ocupações em áreas protegidas (BARRETO et al., 2009b; FERREIRA, 2013).

Os dados revelaram que não há demarcação dos limites físicos nos espaços territoriais especialmente protegidos da amostra. A demarcação compreende também a sinalização, visando garantir que as comunidades locais, os visitantes e os funcionários da UC conheçam seus limites, através da instalação de marcos e de placas indicativas, em pontos estratégicos (FERREIRA, 2013; DARIAS, 2009).

Os dados evidenciaram que $60 \%$ da amostra possui emergências ambientais, totalizando 15.586 hectares de queimadas e 281ha de desmatamento. A Resex do Rio Ouro Preto, detentora da maior área desmatada, caminha numa escalada crescente. No ano de 1997 registrou 77,3km² de desmate, representando 4\% de seu território, em 2015 perfez 196,19km², num total de 10,5\% da área (INPE, 2015). Na Amazônia, o desmatamento e o fogo estão inextricavelmente ligados (ADENEY et al., 2009).

Das três áreas protegidas atingidas pelas queimadas, duas possuem acesso a área por via terrestre, e o ingresso no Parque Nacional da Serra da Cutia têm apenas uma pequena travessia de barco, possuindo a maior população no entorno em relação as demais unidades de conservação da amostra. Já a entrada na Resex Barreiro das Antas se dá partindo de Guajará-Mirim via Rio Novo, com uma demora de oito horas de voadeira na cheia e até quatro dias na seca. Adeney et al. (2009), Nepstad et al. (2001) e Kirby et al. (2006) apontam que as queimadas em áreas protegidas amazônicas próximas de estradas são mais frequentes quando comparadas as mais distantes, não importando a tipologia do espaço protegido.

A pesquisa revelou a total ausência de meios de comunicação nas unidades de conservação da amostra. Contudo, a distância dos centros urbanos é uma realidade premente na região das áreas pesquisadas, sendo fundamental meios de comunicação eficazes visando coibir a prática de danos através de denúncias.

As informações apontaram que a gestão das unidades de conservação é realizada em $80 \%$ da amostra por uma única pessoa, responsáveis por realizar as ações críticas de proteção e prevenção de atividades ilegais na área protegida, como fiscalização, integração com entorno, gestão participativa, recuperação de áreas etc.. A gestão efetiva dos espaços territoriais especialmente protegidos demanda de quantitativo suficiente de acordo com a intensidade do manejo e o nível de pressões e ameaças (BARRETO et al., 2009b; SOTHE et al., 2017).

Os dados evidenciaram praticamente inexistência de projetos de educação ambiental, seja no interior como no entorno das unidades de conservação. Quanto a pesquisa, avaliação e monitoramento há baixa efetividade em todas os espaços protegido. Compondo o cenário apresentado tem-se, em $80 \%$ das unidades de conservações da amostra, espécies ameaçadas de extinção.

\section{Caracterização das infrações ambientais}

Durante o período estudado, foram lavrados 21 autos de infrações ambientais, os quais integraram os processos administrativos em julgamento no CR1 - Porto Velho, relativos as unidades de conservação federais da amostra. A motivação das ações fiscalizatórias, que resultaram no auto de infração, limitou-se a 
três das seis espécies aplicadas pelo ICMBIO: ação planejada, denúncia e plano de fiscalização estabelecido, como se pode visualizar no gráfico 1.

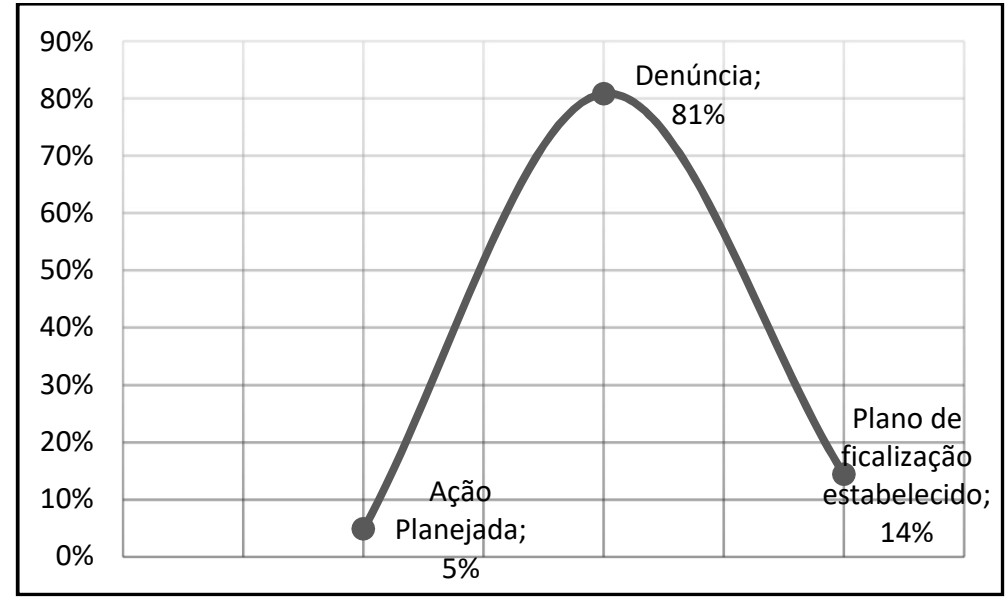

Gráfico 1: Motivação das ações fiscalizatórias.

Evidenciou-se que a ação de fiscalização do tipo denúncia representou o maior percentual, demonstrando que a comunidade extrativa residente nas áreas protegidas tem desempenhado o papel de proteção desses espaços buscando efetivar a conservação dos recursos naturais intrínsecos aos mesmos e, por conseguinte, resguardar seu modo de vida e sua subsistência. Contudo, o quantitativo ínfimo de ações planejadas e planos de fiscalização, que juntos perfizeram menos que $20 \%$, revela uma insipiente iniciativa de ações fiscalizatórias por parte do poder público visando coibir os ilícitos ambientais.

Observou-se que esse contexto se relaciona com a deficiência de recursos humanos apresentado no perfil das unidades de conservação estudadas. Os dados indicaram que quatro áreas protegidas possuem apenas um funcionário, o gestor, para o cumprimento das diversas atividades. Relacionando o quantitativo dos recursos humanos com a média de área das unidades de conservação, verificou-se que cada funcionário se responsabiliza por 239.007,67ha, o que representa uma deficiência de funcionários por área protegida.

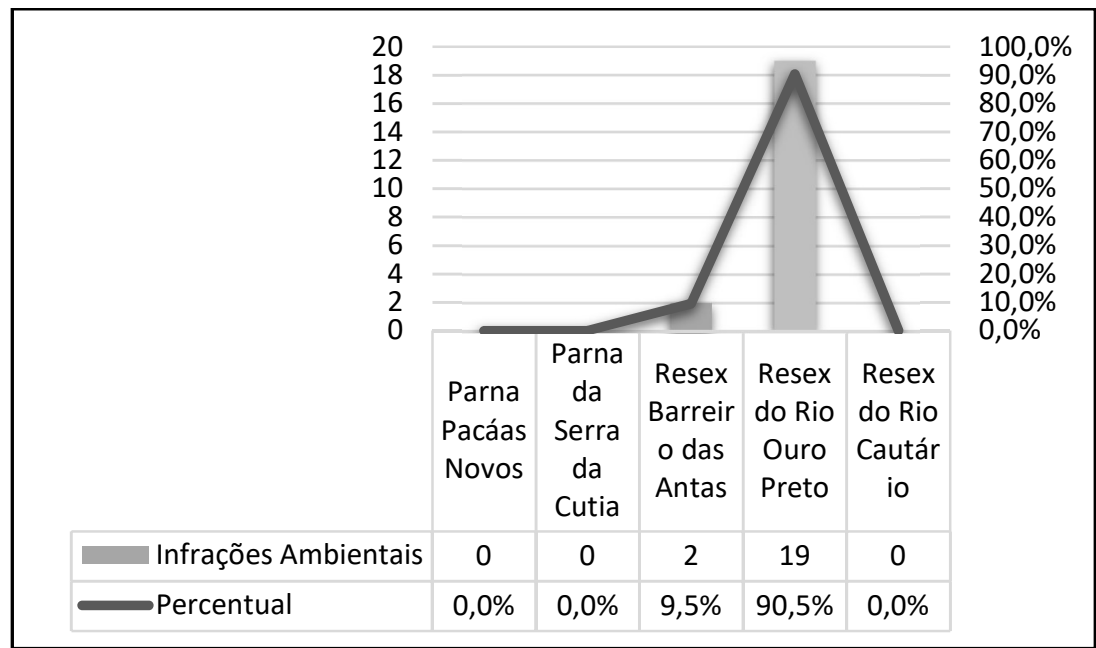

Gráfico 2: Incidência das infrações ambientais por Unidades de Conservação.

Esse cenário corrobora com a realidade nacional insatisfatória quanto ao número de recursos humanos no âmbito ambiental (REIS et al., 2008; SCHIAVETTI et al., 2012). Segundo Ferreira (2013), um 
funcionário para cada 27.560ha da unidade de conservação já é um percentual insuficiente para fiscalização, demonstrando que a realidade dos espaços estudas é, ainda, mais crítica.

Quanto a autuação das infrações a pesquisa apontou que $81 \%$ dos registros ocorreu no interior das unidades de conservação, seguido de 14\% nas áreas circundantes (entorno) e 5\% na zona urbana de GuajaráMirim. Em relação ao quantitativo das ocorrências dos autos de infrações ambientais, a análise revelou que os ilícitos ambientais centraram-se em duas unidades de conservações da amostra, são elas a Resex do Rio Ouro Preto e a Resex Barreiro das Antas, ambas da categoria de uso sustentável, predisposto no gráfico 2. Os dados revelaram que, nos registros pesquisados, inexiste autos de infração em três das cinco unidades de conservação da amostra.

Contudo, na análise do perfil dos Parques Nacionais do Pacaás Novos e da Serra da Cutia, ficou evidenciado que $60 \%$ das áreas de queimadas e desmatamento ocorreram no interior desses espaços protegidos, demonstrando a ocorrência de ilícitos ambientais. Infrações não autuadas simulam uma falsa realidade de pacificação de conflitos, representando sanções não aplicadas e infratores não punidos, o que induz a reincidência nas mesmas práticas e, por conseguinte, outros danos ao ambiente (BARRETO et al., 2009b; CINTRA, 2006; WATSON, 2005).

Os parques nacionais são áreas de proteção integral admitindo apenas o uso indireto dos seus atributos naturais, objetivando a manutenção dos ecossistemas livres de alterações causadas por interferência humana. Portanto, as emergências ambientais relatadas não coadunam com esse perfil preservacionista.

O gráfico 3 aponta a tipologia das infrações ambientais registradas nos autos da análise, totalizando dez espécies de condutas ilícitas previstas em seis artigos do Decreto nำ514/2008, englobando três categorias. Predominaram ilícitos relacionados à fauna, com destaque para os artigos 35, 42 e 93 . As apreensões dos pescados foram doadas para entidades beneficentes. Embora a amostra pesquisada somou 21 processos houve 26 infrações, devido o registro de mais de um ilícito em quatro processos administrativos. Quanto a autoria o gênero masculino predominou em $81 \%$ dos registros, não sendo constado reincidência dos autuados no período estudado.

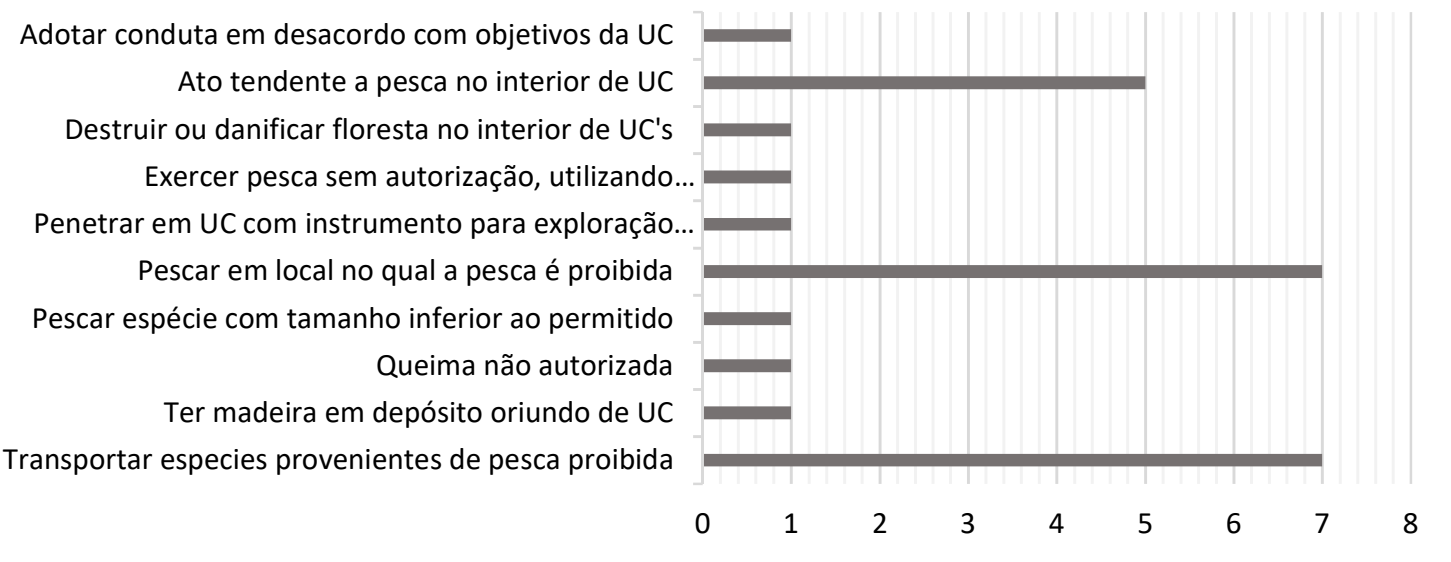

Gráfico 3: Quantitativo das infrações ambientais por tipologia. 
Os dados apontaram que a pesca em local proibido, o transporte desse pescado e o ato tendencioso a pesca no interior de unidade de conservação, resultaram em $73 \%$ das infrações. 0 percentual expressivo do ilícito envolvendo a pesca somado a predominância do gênero masculino como infratores (CINTRA, 2006) apontam o que Nurse (2016) classifica como crime de masculinidade, através da compreensão dos comportamentos e condições que levam ao crime ambiental, percebendo-o como exercício do poder sobre os animais.

Para essa espécie de infrator ambiental o poder sobre os animais está ligado a atividades esportivas ou 'passatempo', percepções pelo ofensor de suas ações fazendo parte de sua cultura onde tenacidade, masculinidade e inteligência combinam com excitação (MESSERSCHMIDT et al., 2016; NURSE, 2011).

O ilícito destruir ou danificar floresta no interior de unidade de conservação implicou na apreensão de 2,611 metros cúbicos de madeira beneficiada, que se encontrava no interior da Resex do Rio Ouro Preto. Esse registro corrobora com o perfil da área protegida, onde a emergência ambiental desmatamento somou 169 hectares no ano de 2016 na Resex, tendo aumentado significativamente desde 1997. O aumento do desmatamento ocorreu simultaneamente à tramitação no Senado Federal da proposta de exclusão de 31.489 hectares da área protegida.

O Projeto de exclusão prevê como justificativa que na criação da área de proteção os limites foram definidos apressadamente, sem uma análise detalhada da situação fundiária, englobando erroneamente uma fração de terras totalmente antropizada, utilizada na exploração da atividade agropecuária (BRASIL, 2007; MARQUES et al., 2014).

Contudo, em consulta as comunidades beneficiárias da Resex a antropização da área diverge do posicionamento dos extrativistas, o que é evidenciado nas imagens de satélite da cobertura florestal entre os anos de 1990 (área quase totalmente intacta) e 2011 (área em processo de desmatamento acelerado), quando o desmatamento na área de exclusão saltou de 8.41\% para 40\% (ICMBIO, 2013).

Segundo Drummond (2003), o desmatamento em espaços territoriais especialmente protegidos integra as três tendências da Resex do Rio Ouro Preto (clivagem social, maior desmatamento e diferenciais de renda), todas contrárias aos objetivos expressos das reservas extrativistas em manter a floresta de pé e promover justiça social com base na coesão de comunidades tradicionais.

\section{Parâmetros de prevenção à crimes ambientais através da green criminology}

As áreas de abrangência da green criminology 'dano e destruição, norma jurídica e regulação ambiental', foram aplicadas aos dados do perfil genérico das unidades de conservação e aos padrões identificados nos autos de infração ambiental, verificando-se três parâmetros de prevenção à infrações ambientais, para serem empregados em áreas protegidas em situações análogas aos espaços territoriais especialmente protegidos analisados na amostra da pesquisa.

$\mathrm{Na}$ área do dano ambiental, identificou-se ações de fiscalização ao capital natural em áreas protegidas enquanto parâmetro preventivo (BARRETO et al., 2009b; ODUM et al., 2011). A deficiência na fiscalização é uma grande dificuldade no cumprimento dos objetivos das unidades de conservação 
(BROCKELMAN et al., 2002; LIMA et al., 2005), pois frequentemente não há testemunhas ou vítimas humanas diretas ou, quando existem, são envolvidos no crime como empregados, assim as infrações ambientais, normalmente, só podem ser detectadas por meio de controlo externo (HUISMAN et al., 2013). Portanto, evitar a ocorrência de danos pela vigilância sistemática e prioritária das áreas protegidas é o ponto central de uma governança ambiental com vistas a uma política de monitoramento inibitório de ilícitos (MELLOTHERY, 2011; ROUSSEAU et al., 2010).

Contudo, a prevenção das infrações ambientais, por meio das ações de fiscalização, demanda de disponibilização de recursos para que os órgãos de controle se aparelhem com equipamentos adequados e quantitativo de agentes especializados suficientes, para garantir a supervisão de áreas tão extensas e com caracteristicas peculiares como as unidades de conservação da amostra (COSTA, 2012; CINTRA, 2006; SCHIAVETTI et al., 2012). As inspeções diferenciadas podem auxiliar com a ruptura das resistências às medidas corretivas através da ação interativa entre os órgãos de fiscalização e defesa legal do meio ambiente, garantindo a manutenção da qualidade ambiental, na perspectiva de priorizar a conservação dos recursos naturais (BARRETO et al., 2009b; CINTRA, 2006)

$\mathrm{Na}$ área da regulação ambiental o parâmetro preventivo identificado foi a regularização fundiária, enquanto instrumento de justiça ambiental. Problemas recorrentes como o racismo ambiental, influenciado por relações de poder na sociedade, corroboram com a inércia em implementar as medidas de resolução das questões fundiárias em unidades de conservação, atingindo, no caso das áreas de uso sustentável, um grupo cultural específico que são as comunidades tradicionais.

O racismo ambiental é premente na Amazônia, especificamente quanto ao caso da Resex do Rio Ouro Preto o receio dos extrativistas às ameaças dos posseiros, resultou em divisão dos residentes quanto a exclusão de parte da área, o que, caso ocorra de fato, ocasionará um impacto significativo ao ambiente. Portanto, a regulação ambiental através da resolução da questão fundiária é um inibidor de conflitos e, por conseguinte, de danos ambientais.

Destarte, a regularização fundiária implica em justiça ambiental enquanto uma forma de tomada de decisão quanto a concessão de direito real de uso dos espaços protegidos à minoria étnica das populações tradicionais (CINTRA, 2006; DAVIES, 2014; STRETESKY, 2003; WHITE, 2007). Assim, através desse modelo de regulação, é demonstrado ações de menor resistência política a tal maneira de opressão ambiental, conexa a sistemas econômicos e políticos (LYNCH et al., 2015; LYNCH, 2013; ZILNEY et al., 2006).

A educação ambiental revelou-se como segundo parâmetro preventivo na área de regulação ambiental. Há muito as discussões acerca da temática educação ambiental são controversas, contudo sua apresentação como tipologia de prevenção é direcionada ao modo de percepção da infração ambiental. Embora já haja um dano advindo da conduta ilícita, sua análise científica será relevante na compreensão situacional da área protegida (HUISMAN et al., 2013; EDWARDS et al., 1996), com vistas a não replicação do ato, pois "o reconhecimento de um problema é o primeiro passo na formulação de soluções" (SEIS, 1996).

Esta continua a ser a tarefa mais crítica, pois, as áreas da amostra apresentaram baixa efetividade no desenvolvimento de pesquisas relacionadas à unidade de conservação. Contraposto, países desenvolvidos 
disponibilizam bolsas de estudos para pesquisas concentradas em green criminology (SOUTH et al., 2014b), enquanto inexiste estudos da teoria na América Latina (FLORES et al., 2017).

Os programas de pesquisas acadêmicas são instrumentos relevantes para o desenvolvimento de estudos relativos a prevenção situacional do dano, vez que oferecem o conhecimento baseado em respostas a questões emergentes, através de análises científicas (MILLER-RUSHING et al., 2017; EDWARDS et al., 1996). Apenas com o conhecimento dos múltiplos fatores e atores é possível designar ações e procedimentos preventivos ou, ainda, políticas públicas pautadas na governança ambiental (ZHOURI, 2008; PRIEUR, 1996).

\section{CONCLUSÕES}

A identificação do perfil genérico das unidades de conservação descreveu o panorama das áreas, possibilitando a percepção da realidade vivenciada por tais espaços. A identificação das emergências ambientais, queimadas e desmatamento, a inexistência de demarcações dos limites das terras e o percentual de áreas com problemas de regularização fundiária revelam um cenário de pressões e ameaças latentes, propício a ocorrência de infrações ambientais e, por conseguinte, danos ambientais.

Como resultado desse panorama tem-se a existência de espécies ameaçadas de extinção, emergindo como um indicador de dano de difícil controle e reversibilidade, considerando que fatores diversos (à exemplo das pressões e ameaças citadas) precisam serem controladas para interromper esse ciclo danoso. O estudo das infrações ambientais propiciou o conhecimento das condutas ilícitas e, assim, o entendimento das circunstâncias em que tais são praticadas.

Os resultados apontaram divergência quanto a ausência de registro das infrações ambientais em três unidades de conservação estudadas, considerando que tais áreas apresentaram pressões e ameaças prementes no interior e na área circundante. A inexistência de moradores nos parques nacionais, considerando sua natureza de proteção integral, impossibilitou denúncias das condutas nocivas, reafirmando a característica presente nos autos de infração de start por meio de denúncia dos residentes das áreas protegidas e não através de ações planejadas.

Através da sobreposição do perfil genérico das unidades de conservação e dos padrões das condutas nocivas ao ambiente, às áreas de abrangência da green criminology (dano ambiental, norma jurídica, regulamentação), foi possível identificar três parâmetros preventivos à danos ambientais a serem aplicados nas unidades de conservação em situações análogas às áreas protegidas da pesquisa, visando acautelar a ocorrência das infrações ambientais.

Podemos citar: ações de fiscalização ao capital natural em áreas protegidas; regularização fundiária, enquanto instrumento de justiça ambiental; e educação ambiental enquanto modo de percepção da infração ambiental através da compreensão situacional. Somente a implantação das unidades de conservação não legitima a preservação ambiental. Prevenção a danos ambientais são e serão, sempre, a forma mais eficaz de controlar os impactos negativos ao ambiente. 


\section{REFERÊNCIAS}

ADENEY, J. M.; CHRISTENSEN JR., N. L.; PIMM, S. L.. Reserves Protect against Deforestation Fires in the Amazon. PLoS ONE, Reino Unido, v.4, n.4, 2009. DOI: https://doi.org/10.1371/journal.pone.0005014

BARATA, A. N.. Ambiente e ordenamento do território: a questão ambiental dos desmatamentos em áreas protegidas na Amazônia. Dissertação (Mestrado) - Universidade de Coimbra, Coimbra, 2011

BARRETO, P.; ARAÚJO, E.; BRITO, B.. A impunidade de crimes ambientais em áreas protegidas federais na Amazônia. Belém: Instituto do Homem e Meio Ambiente da Amazônia, 2009a.

BARRETO, P.; MESQUITA, M.. Como prevenir e punir infrações ambientais em áreas protegidas na Amazônia?. Belém: Instituto do Homem e Meio Ambiente da Amazônia, 2009b.

BECK, U.. Sociedade de risco: rumo a uma outra modernidade. 2 ed. São Paulo: Editora 34, 2011.

BERNARD, E.; PENNA, L. A. O.; ARAÚJO, E.. Downgrading, Downsizing, Degazettement, and Reclassification of Protected Areas in Brazil. Conservation Biology, v.28, p.939950, 2014. DOI: http://doi.org/10.1111/cobi.12298

BRAGA, R.. Direito e gestão ambiental. Rio de Janeiro: Esplanada, 2004

BRASIL. Decreto n.6.514 de 22 de julho de 2008. Dispõe sobre as infrações e sanções administrativas ao meio ambiente, estabelece o processo administrativo federal para apuração destas infrações, e dá outras providências. Brasília: DOU, 2008

BRASIL. Lei n.9985 de 18 de julho de 2000. Regulamenta o art. 225, §1으, incisos I, II, III e VII da Constituição Federal, institui o Sistema Nacional de Unidades de Conservação da Natureza e dá outras providências. Brasília: DOU, 2000.

BRASIL. Projeto de Lei n.206 de 2007. Exclui uma fração da área da Reserva Extrativista do Rio Ouro Preto, localizada nos municípios de Guajará-Mirim e Vila Nova Mamoré, no Estado de Rondônia. Brasília: Senado Federal, 2007.

BROCKELMAN, W. Y.; GRIFFITHS, M.. Mecanismos de fortalecimento das áreas protegidas. In: TERBORGH, J.; SCHAIK, C. V.; DAVENPORT, L.. Tornando os parques eficientes: estratégias para conservação da natureza nos trópicos. Curitiba: Universidade Federal do Paraná, 2002. p.290-304.

CINTRA, R. H. S.. Qualitative and quantitative analysis of environmental damages through instauration and registers of lawful documents. Brazilian Archives of Biology and Technology, Curitiba, v.49, n.6, p.989-999, 2006. DOI: http://doi.org/10.1590/S1516-89132006000700017

COSTA, L.. Privacy and the precautionary principle. Computer Law \& Security Review, v.28, n.1, p.14-24, 2012. DOI: http://doi.org/10.1016/i.clsr.2011.11.004

DARIAS, A. J. R.. ¿Áreas protegidas frente a la presión territorial más allá de sus límites?: La patrimonialización de los macizos de Anaga y Teno (Tenerife, Islas Canarias, España). Estudios y Perspectivas en Turismo, v.18, n.3, p.341-356, 2009

DAVIES, P. A.. Green crime and victimization: tensions between social and environmental justice. Theoretical Criminology, v.18, n.3, p.300-316, 2014. DOI: https://doi.org/10.1177/1362480614522286

DRUMMOND, J. A.. Anotações de um integrante de bancas examinadoras: teses e dissertações defendidas recentemente na área de Ciências Ambientais. Ambiente \& Sociedade, Campinas, v.5, n.2, p.191-214, 2003. DOI: http://doi.org/10.1590/S1414-753X2003000200011

DUDLEY, N.; PHILLIPS, A.. Forests and Protected Areas: guidance on the use of the IUCN protected area management categories. Cambridge: IUCN, 2006.

EDWARDS, S. M.; EDWARDS, T. D.; FIELDS, C. B. Environmental crime and criminality: theoretical and practical issues. Londres: Garland Publishing, 1996.

ELVAN, O. D.. Forest offences in 21st Century Turkey (with the example for the offender and trial period of illegal use of the forests in Istanbul). International Journal of Law, Crime and Justice, v.42, n.4, p.324-339, 2014. DOI: https://doi.org/10.1016/i.ijlcj.2014.04.002

FERREIRA, G. H. C.. Regularização fundiária e as unidades de conservação no Brasil: um desencontro histórico. Agrária, São Paulo, n.18, p.76-113, 2013. Dol: http://doi.org/10.11606/issn.1808-1150.v0i18p76-113

FLORES, C. R.; KONRAD, O.; FLORES, J. A.. Green criminology: cenário das produções científicas. Revista Ibero-Americana em Ciências Ambientais, Aracaju, v.8, n.3, 2017.

HOBSBAWM, E.. Era dos extremos: o breve século XX 1914-1991. São Paulo: Companhia das Letras, 1995.

HUISMAN, W.; VAN ERP, J.. Opportunities for environmental crime: a test of situational crime prevention theory. The British Journal of Criminology, v.53, n.6, p.1178-1200, 2013. DOI: https://doi.org/10.1093/bjc/azt036

ICMBIO. Instituto Chico Mendes da Biodiversidade. Consulta às comunidades beneficiárias da Reserva Extrativista do Rio Ouro Preto sobre o PL 207/2006. Guajará-Mirim: ICMBIO, 2013.

ICMBIO. Instituto Chico Mendes para a Conservação da Biodiversidade. Método para Avaliação Rápida e a Priorização da Gestão de Unidades de Conservação Rappam. Brasília: ICMBIO, 2015.

INPE. Instituto Nacional de Pesquisas Espaciais. Desmatamento nas Unidades de Conservação. Brasília: INPE, 2015.

IUCN. União Internacional para a Conservação da Natureza. Protected Planet Report 2016. Cambridge: IUCN, 2016.

KIRBY, K. R.; LAURANCE, W. F.; ALBERNAZ, A. K.; SCHROTH, G.; FEARNSIDE, P. M.; BERGEN, S.; VENTICINQUE, E. M.; COSTA, $C$.. The future of deforestation in the Brazilian 
Amazon. Futures, v.38, n.4, p.432-453, 2006. DOI: http://doi.org/10.1016/i.futures.2005.07.011

LEFF, E.. Complexidade, racionalidade ambiental e diálogo de Saberes. Educação e Realidade, Porto Alegre, v.34, n.3, p.17-24, 2009.

LIMA, G. S.; RIBEIRO, G. A.; GONCALVES, W.. Avaliação da efetividade de manejo das unidades de conservação de proteção integral em Minas Gerais. Revista Árvore, v.29, n.4, p.647-653, 2005. DOI: http://doi.org/10.1590/S0100$\underline{67622005000400017}$

LYNCH, M. J.; LONG, M. A.; BARRETT, K. L.; STRETESKY, P. B.. Is it a crime to produce ecological disorganization? Why green criminology and political economy matter in the analysis of global ecological harms. The British Journal of Criminology, v.53, n.6, p.997-1016, 2013. DOI: https://doi.org/10.1093/bjc/azt051

LYNCH, M. J.; STRETESKY, P. B.; LONG, M. A.. Environmental justice: a criminological perspective. Environmental Research Letters, v.10, n.8, p.1-6, 2015. DOI: https://doi.org/10.1088/1748-9326/10/8/085008

MARQUES, A. A. B.; PERES, C. A.. Pervasivas ameaças legais para áreas protegidas no Brasil. Oryx, Reino Unido, v.49, n.1, p.25-29, 2015. DOI:

http://doi.org/10.1017/S0030605314000726

MEDEIROS, R. A.. Proteção da natureza: das estratégias internacionais e nacionais às demandas Locais. Tese (Doutorado em Geografia) - Universidade Federal do Rio de Janeiro, Rio de Janeiro, 2003.

MELLO-THERY, N. A.. Conservação de áreas naturais em São Paulo. Estudos Avançados, São Paulo, v.25, n.71, p.175-188, 2011. DOI: http://doi.org/10.1590/S010340142011000100012

MESSERSCHMIDT, J. W.; TOMSEN, S.. Masculinities, Crime, and Criminal Justice. Oxford: Universidade de Oxford, 2016.

MILLER-RUSHING, A. J.; PRIMACK, R. B.; M. A. K.; ZHOU, Z.. A chinese approach to protected areas: a case study comparison with the United States. Biological Conservation, v.210, p.101-112, 2017. DOI:

http://doi.org/10.1016/j.biocon.2016.05.022

NEPSTAD, D.; CARVALHO, G.; BARROS, A. C.; ALENCAR, A.; CAPOBIANCO, J. P.; BISHOP, J.; MOUTINHO, P.; LEFEBVRE, P.; SILVA, U. L.; PRINS, E.. Road paving, fire regime feedbacks, and the future of Amazon forests. Forest Ecology and Management, v.154, n.3, p.395-407, 2001. DOI: http://doi.org/10.1016/S0378-1127(01)00511-4

NICOLLE, S.; LEROY, M.. Advocacy coalitions and protected areas creation process: case study in the Amazon. Journal of Environmental Management, v.198, p.99-109, 2017. DOI: http://doi.org/10.1016/j.jenvman.2017.04.035

NURSE, A.. An introduction to environmental \& justice. Londres: SAGE, 2016.

NURSE, A.. Policing wildlife: perspectives on criminality in wildlife crime. Papers from the British Criminology Conference, v.11. p.38-53, 2011.
ODUM, E. P.; BARRET, G. W.. Fundamentos de ecologia. 5 ed. São Paulo: Cengage Learning, 2011.

PINHEIRO, V. B.. Sistema de responsabilização de crimes ambientais praticados em unidades de conservação no município de Manaus. Dissertação (Mestrado

Profissionalizante em Gestão de Áreas Protegidas) - Instituto Nacional de Pesquisas da Amazônia, Manaus, 2015.

PRIEUR, M.. Droit de l'Environment. 3 ed. Paris: Dalloz, 1996.

PUCCI, R. D.. Regulierungstechniken für Umweltdelikte und Restorative Justice. Revista da Faculdade de Direito, Universidade de São Paulo, São Paulo, v.108, p.531-541, 2013. DOI: http://doi.org/10.11606/issn.23188235.v108i0p531-541

REIS, T.; MAGALHÃES, J. C.. Fiscal do IBAMA cuida de área igual a 3 cidades de São Paulo. São Paulo: UOL, 2008.

REYDON, B. P.. O desmatamento da floresta amazônica: causas e soluções. Política Ambiental, Belo Horizonte, n.8, p.143-155, 2011.

ROTH, R. E.. Spatiotemporal crime analysis in U.S. law enforcement agencies: Current practices and unmet needs. Government Information Quarterly, Volume 30, n.3, p.226240, 2013. DOI: http://doi.org/10.1016/i.giq.2013.02.001

ROUSSEAU, S.; TELLE, K.. On the existence of the optimal fine for environmental crime. International Review of Law and Economics, v.30, n.4, p. 329-337, 2010. DOI: https://doi.org/10.1016/j.irle.2010.08.004

SCHIAVETTI, A.; MAGRO, T. C.; SANTOS, M. S.. Implementação das unidades de conservação do corredor central da Mata Atlântica no estado da Bahia: desafios e limites. Revista Árvore, Viçosa, v.36, n.4, p.611-623, 2012. DOI: http://doi.org/10.1590/S0100-67622012000400004

SEIS, M.. A native american criminology of environmental crime. In: EDWARDS, S. M.; EDWARDS, T. D.; FIELDS, C. B. Environmental crime and criminality: theoretical and practical issues. Londres: Garland Publishing, 1996.

SOTHE, C.; GOETTEN, L. C.. Infrações Ambientais Constatadas Pela Polícia Ambiental no Litoral Centro-Norte de Santa Catarina. Floresta e Ambiente, Seropédica, v.24, 2017.

SOUTH, N.; BRISMAN, A.; MCCLANAHAN, B.. Green Criminology. Oxford: Universidade de Oxford, 2014a. DOI: http://doi.org/10.1093/OBO/9780195396607-0161

SOUTH, N.; WHITE, R.. The antecedents and emergence of a 'Green' criminology. In: AGNEW, R.. Annual meeting presidential papers: selected papers from the presidential panels: expanding the core: neglected crimes, groups, causes and policy approaches. Atlanta: American Society of Criminology, 2014b.

STRETESKY, P. B.. The Distribution of Air Lead Levels Across U.S. Counties: Implications for the Production of Racial Inequality. Sociological Spectrum, v.23, n.1, p.91-118, 2003. DOI: http://doi.org/10.1080/02732170309207

WATSON, M.. Environmental offences: the Reality of Environmental Crime. Environmental Law Review, v.7, n.3, 
p.190-200, 2005.

DOI: https://doi.org/10.1350/enlr.2005.7.3.190

WHITE, R.. Environmental issues and the criminological imagination. Theoretical Criminology, v.7, n.4, p.483-506, 2003. DOI: https://doi.org/10.1177/13624806030074005

WHITE, R.. Green criminology and the pursuit of social and ecological justice. In: BEIRNE, P.. Issues in green

criminology. Devon: 2007. p.32-54.
ZHOURI, A.. Justiça ambiental, diversidade cultural e accountability: desafios para a governança ambiental. Revista Brasileira de Ciências Sociais, v.23, n.68, p.97-107, 2008.

ZILNEY, L. A.; MCGURRIN, D.; ZAHRAN, S.. Environmental justice and the role of criminology: an analytical review of 33 years of environmental justice research. Criminal Justice Review, v.31, n.1, p.47-62, 2006. DOI: https://doi.org/10.1177/0734016806288258 